\title{
Towards an optimal sampling strategy for Alexandrium catenella (Dinophyceae) benthic resting cysts
}

\author{
B. Genovesi ${ }^{\mathrm{a},{ }^{*}}$, D. Mouillot ${ }^{\mathrm{a}}$, A. Vaquer $^{\mathrm{a}}$, M. Laabir $^{\mathrm{a}}$ and A. Pastoureaud ${ }^{\mathrm{b}}$ \\ aUMR 5119 CNRS-UM2-IFREMER Ecosystèmes Lagunaires, Université Montpellier II-cc 093, 34095 Montpellier \\ Cedex 05, France \\ ${ }^{b}$ Ifremer LER/LR, BP 171, Boulevard Jean Monnet, 34203 Sète, France \\ *: Corresponding author : B. Genovesi, email address : genovesi@univ-montp2.fr
}

\begin{abstract}
:
The study proposes methodological developments to optimize sampling strategy of resting cysts of Alexandrium catenella to estimate their abundance with a predefined error. This work also aims to provide information on spatial distribution of resting cysts in sediments. The distribution mode of $A$. catenella resting cysts related to the abundance variability was studied through sediment cores sampling on four different spatial scales and using Ludox CLX gradient density method. The quantification method underestimates by a factor of 2 the resting cysts abundance in one gram of sediment. Application of Taylor's power law allowed us to define a compromise between sampling effort and abundance estimation error. In the case of $A$. catenella resting cysts from Thau lagoon, the optimal sampling strategy consists of sampling 10 stations on a surface of $2 \mathrm{~km} 2$ for a given coefficient of variability $(C)$ of $15 \%$, sampling 3 sediment cores at each station $(C=30 \%)$ and counting only one replicate by core $(C=18 \%)$. Results related to the application of Taylor's power law are closely dependent on resting cyst density and aggregation in a given sediment. In our area, A. catenella resting cysts are mainly observed in the upper $3 \mathrm{~cm}$ of sediment. Horizontally, their heterogeneity is lower on $10 \mathrm{~cm} 2$ surface and tends to stabilize itself beyond a surface of $10 \mathrm{~m} 2$. Each author has to carry out this pre-sampling effort for his own resting cysts-forming species, in his own area, in order to increase accuracy of resting cyst mapping.
\end{abstract}

Keywords: Alexandrium catenella; Toxic dinoflagellate; Resting cyst; Optimum sample size; Spatial distribution; Vertical profiles 


\section{Introduction}

Shellfish farming activities in Thau lagoon (South France) have been threatened since 1998 by recurrent toxic blooms of Alexandrium catenella (Lilly et al., 2002). The blooms seasonal pattern is related to resting forms. Like $10 \%$ of 2000 dinoflagellate species, $A$. catenella produces benthic resting cysts (Dale, 1983) whose excystment constitutes the starting point of their planktonic life cycle. "Cyst banks" of sediments play a key role in the bloom initiation phase (Anderson et al., 1982; Garcés et al., 1999; McGillicuddy et al., 2003). Understanding the initiation mechanism implies the acquisition of robust data on resting cysts distribution and density.

Resting cysts are mainly distributed at the sediment surface (Irwin et al., 2003; Garcés et al., 2004; Mizushima and Matsuoka, 2004). Their concentration increases in muddy sediment with water and organic matter contents (Erard-Le-Denn et al., 1993; Yamaguchi et al., 1996). However, the observed variations in resting cysts distribution and density could be linked to the encystment capability of planktonic species in the water column, sedimentation, transport and bioturbation processes (Anderson, 1997, Garcés et al., 2004; Joyce et al., 2005). Mud sediment combined with high sedimentation rate promotes resting cysts burying (Anderson et al., 1982; Godhe and Mcquoid, 2003). Resuspension can affect their distribution (Kirn et al., 2005) and bioturbation contributes to their vertical redistribution into the sediment (Anderson et al., 1982; Giangrande et al., 2002). All these processes result in heterogeneous distribution of resting cysts (Garcés et al., 2004). Consequently, an inappropriate sampling scale can hide spatial heterogeneity and lead to wrong conclusions (Blanchard, 1990).

A significant effort has been realized over the last 20 years to develop quantification methods (Table 1). However, sampling method, analysed sediment layer, quantification 
method and units used have varied highly among authors and prevent between-site comparisons. Sampling methods vary from using a simple grab to more elaborate coring systems. Quantification methods also vary and depend on the combination between sonication and sieving or more elaborated methods, in particular palynology or gradient density methods. In contrast, the development of sampling strategy has been neglected even though it compromises the precision of the reported mapping of benthic resting cysts. Choosing an appropriate spatial sampling schema is a recurring problem in environmental studies (Mouillot et al., 1999). Better understanding of the spatial distribution of a given population has allowed a certain number of efficient sampling strategies to be developed which takes into consideration a predetermined result accuracy (Thistlewood, 1989; Ho, 1993).

For these reasons, this work aims to describe a sampling strategy adjusted to the quantitative study of benthic resting cysts. Our main objectives are: (i) to define the best compromise between measuring precision of resting cyst densities and sampling effort as a function of spatial scale; (ii) to define the yield of a modified method for resting cyst quantification, i.e. the ludox CLX density gradient method; (iii) to describe horizontal and vertical distribution modes of $A$. catenella resting cysts in Thau lagoon.

\section{Methods}

\subsection{Study area}

Thau lagoon is located $30 \mathrm{~km}$ South-West of the city of Montpellier (Hérault, France)

(Fig. 1). Its surface reaches $75 \mathrm{~km}^{2}$ in $1 / 5$ of which shellfish farming structures reside. This shallow lagoon (mean depth $<4.5 \mathrm{~m}$ ) is connected to the Mediterranean Sea through 
numerous channels. The sampling was carried out in creek of l'Angle (Fig. 1) which is the only place where A. catenella blooms started and showed maximum vegetative cell densities (unpublished data). This shallow (mean depth $<2.5 \mathrm{~m}$ ) and semi-enclosed area has a surface of $2 \mathrm{~km}^{2}$ and receives fresh water supplies particularly from the Vène River. For the survey of A. catenella vegetative cell dynamics in the water column, a sampling grid with a mesh of 100 m was applied and 27 stations located by GPS were established and distributed along 3 transects: transect $\mathrm{B}$ (stations $\mathrm{B}_{2}$ to $\mathrm{B}_{6}$ ) located on the West shore of the creek; central transect A (stations $\mathrm{A}_{000}$ to $\mathrm{A}_{10}$ ) extending from the creek bottom to the beginning of the shellfish farming structures, and transect $\mathrm{C}$ (stations $\mathrm{C}_{1}$ to $\mathrm{C}_{7}$ ) located on the East shore. Two stations were also located at the north extremity of the creek $\left(\mathrm{L}_{2}\right.$ and $\left.\mathrm{L}_{3}\right)$.

\subsection{Sediment sampling}

The first sampling campaign was carried out on $7^{\text {th }}$ and $13^{\text {th }}$ August 2003 before the autumnal bloom. Our sampling strategy allowed us to obtain six dataset series: one series for the stations $\mathrm{A}_{00}, \mathrm{~A}_{6}$ and $\mathrm{C}_{5}$ and three series for station $\mathrm{A}_{3}$. Each dataset series was sampled by 16 sediment cores located in a quadrat $(3 \mathrm{~m} \times 3 \mathrm{~m})$ divided by a mesh of $1 \mathrm{~m} \times 1 \mathrm{~m}$ and corresponding to $9 \mathrm{~m}^{2}$ of surface. In each series, 12 additional sediment cores were sampled on a central sub-quadrat $(1 \mathrm{~m} \times 1 \mathrm{~m})$ divided by a mesh of $0.33 \mathrm{~m} \times 0.33 \mathrm{~m}$ and corresponding to $1 \mathrm{~m}^{2}$ of surface. Overall, 28 sediment cores were taken at each sampling station (Fig. 2). The variability between samples was studied on the basis of one count by sediment core. The variability within a sample, i.e. within a sediment core, was studied on the basis of triplicate counts for 72 sediment cores out of 112 cores sampled. In order to describe the vertical profile of $A$. catenella resting cysts at each $\mathrm{A}_{00}, \mathrm{~A}_{3}$ and $\mathrm{A}_{6}$ stations, one sampled sediment core was cut every $3 \mathrm{~cm}$ for the total height of available sediment core (up to 40 
$\mathrm{cm})$. The variability within sediment layers was studied on the basis of triplicate counts by sediment layers.

After A. catenella autumnal bloom, 24 stations of the creek of l'Angle grid were sampled on $31^{\text {st }}$ March and $1^{\text {st }}$ April 2004. The second sampling campaign covered a studied surface of around $2 \mathrm{~km}^{2}$. Sampling was carried out on the basis of triplicate sediment cores in each sampling station. Resting cyst densities were evaluated on the basis of one count per sediment core.

Sediment sampling was performed by scuba divers using core samplers $(75 \mathrm{~mm}$ of diameter and 200 to $400 \mathrm{~mm}$ of length). The top $3 \mathrm{~cm}$ of sediment core were sliced out (Schwinghamer et al., 1991; Yamaguchi et al., 1995; Cho and Matsuoka, 2001; Laabir et al., 2004) and stored less than 4 months at $6^{\circ} \mathrm{C}$ in dark until analysis.

\subsection{Resting cyst distribution}

In order to study the spatial distribution of A. catenella resting cysts and its associated variability, and to determine optimum sample size, the first $3 \mathrm{~cm}$ of sediment of 4 increasing spatial scales were analysed. Each spatial scale was related to a given surface sampled with a given mesh. The smallest spatial scale corresponded to the surface of a sediment core of 0.04 $\mathrm{m}^{2}$. In this case, there was no true sampling mesh, sediment samples were taken randomly in the first $3 \mathrm{~cm}$ of the core. The second and third spatial scales corresponded respectively to a surface of $1 \mathrm{~m}^{2}$ which was studied through the sub-quadrat $(1 \mathrm{~m} \times 1 \mathrm{~m})$ divided by a mesh of $0.33 \mathrm{~m} \times 0.33 \mathrm{~m}$ and to a surface of $9 \mathrm{~m}^{2}$ which was studied through the quadrat $(3 \mathrm{~m} \times 3 \mathrm{~m})$ divided by a mesh of $1 \mathrm{~m} \times 1 \mathrm{~m}$. The fourth spatial scale corresponded to the surface of creek 
of l'Angle which reaches approximately $2 \mathrm{~km}^{2}$. This last spatial scale was studied through the sampling grid with a $100 \mathrm{~m}$ mesh.

\subsection{Resting cysts separation}

Resting cysts were separated from sediments according to the Ludox centrifugation method (Erard-Le Denn and Boulay, 1995; Yamaguchi et al., 1995). Resting cysts were concentrated in a density gradient which was produced by a fluid having a density equivalent to that of resting cyst, i.e. nearly $1.3 \mathrm{~g} \mathrm{~cm}^{-3}$ (Blanco, 1986). Ludox CLX is a very viscous industrial chemical containing silica colloids. Because of its solidification in salt water, we washed and stored sediment samples in distilled water (Schwinghamer et al., 1991; Erard-Le Denn and Boulay, 1995; Yamaguchi et al., 1995).

\subsubsection{Preparation of sediment fine fraction}

The top $3 \mathrm{~cm}$ of the sediment core were homogenised (Erard-Le-Denn and Boulay, 1995; Godhe et al., 2000). Aliquots ( $1 \mathrm{~g}$ of wet sediment) were removed and suspended in 50 $\mathrm{ml}$ of distilled water (Yamaguchi et al., 1995) prior to 3 minutes of sonication (Bandelin SONOREX RK $100 \mathrm{H}$ ), to separate resting cysts from other particles (An et al., 1992; ErardLe-Denn and Boulay, 1995; Laabir et al., 2004), and to clean resting cysts from their mucus which facilitates sieving and observations (Persson et al., 2000). As A. catenella resting cysts mean size was $41.8 \mu \mathrm{m}$ by $30.4 \mu \mathrm{m}$ (Laabir et al., 2004), the slurry was first sieved on a 80 $\mu \mathrm{m}$ nylon membrane (Millipore). After washing the membrane with distilled water, the filtrate was sieved again on a $20 \mu \mathrm{m}$ nylon membrane (Millipore). The sieve was placed in a polypropylene tube filled with $5 \mathrm{ml}$ of distilled water. The tube was shaken to separate the 
sediment from the membrane prior to a second sonication for 3 min. The membrane was mechanically shaken by flat board tweezers and then removed. The sediment fraction between 20 and $80 \mu \mathrm{m}$ was resuspended in $5 \mathrm{ml}$ of distilled water (Fig. 3).

In order to estimate losses related to $80 \mu \mathrm{m}$ sieving, the sieve was conserved, suspended in $5 \mathrm{ml}$ of distilled water and was sonicated during 3 minutes. The sieve was then placed in a polypropylene tube prepared with $5 \mathrm{ml}$ of distilled water. The tube was shaken prior to sonication. The membrane was removed as mentioned above. This process was repeated successively three times and in triplicate (Fig. 3).

\subsubsection{The Ludox CLX density gradient method}

The sediment fraction remaining between 20 and $80 \mu \mathrm{m}$ was transferred to a $50 \mathrm{ml}$ tube, and then $5 \mathrm{ml}$ of Ludox CLX $50 \%$ and $5 \mathrm{ml}$ of Ludox CLX $100 \%$ were added successively. The tube was centrifuged during 30 minutes at 3000 revolutions $\min ^{-1}$ and at $4^{\circ}$ C. Centrifugation allowed sedimentation and floatation of particles which were distributed in the different density layers by affinity. The resting cysts were concentrated in the upper fraction. This unstable phase must be extracted quickly with a Pasteur pipette and then sieved on a $20 \mu \mathrm{m}$ nylon membrane (Millipore). After a meticulous wash, the sieve was placed in a

tube filled with $5 \mathrm{ml}$ of distilled water. The tube was shaken and sonicated 3 minutes. Then the sieve was removed and the remaining slurry constituted the sample for resting cyst numeration (Fig. 3).

As suggested by Yamaguchi et al. (1995), centrifugation with a density gradient could underestimate the density of resting cysts in a sediment sample. In order to estimate the method yield, the pellet issued from centrifugation was resuspended with $5 \mathrm{ml}$ of distilled water and treated successively six times according to the same protocol for 11 sediment 
samples. To complete this procedure, sonicating efficiency (3 minutes) was tested. Following the last ultrasound exposure, the removed $20 \mu \mathrm{m}$ sieve was resuspended in $5 \mathrm{ml}$ of distilled water and treated three times successively according to the same protocol for 6 sediment samples (Fig. 3).

\subsection{The sediment water content}

Nearly $20 \mathrm{~g}$ of wet sediment were homogenised and put into a glass dish. The wet weight $(\mathrm{Ww})$ was measured prior to an exposure at $60^{\circ} \mathrm{C}$ for 7 days in order to measure the dry weight $(\mathrm{Wd})$. The water content was calculated by the following formula: water content $(\%)=[(\mathrm{Ww}-\mathrm{Wd}) \times 100] / \mathrm{Ww}$.

As suggested by Cho and Matsuoka (2001), the expression of resting cysts number by gram of dry sediment allowed to decrease variability, in particular that which related to sediment water content. This may facilitate between-site comparisons. The resting cyst density was expressed in resting cysts by gram of dry sediment through the formula: cysts $\mathrm{g}^{-1}$ dry sediment $=$ cysts $g^{-1}$ wet sediment $/[1-($ water content $/ 100)]$.

\subsection{Resting cysts quantification}

The sample $(5 \mathrm{ml})$ was transferred to a well of a 12 multiwells-plate and was left to rest for 1 hour. Counts were performed with a photonic inverted microscope (Zeiss Axiovert 25) at a magnification of $100 \times$ or $200 \times$.

\subsection{Statistical processing}


In the present study, Taylor's power law was used to quantify the spatial dispersion of A. catenella resting cysts in the sediment, and to develop an optimal sampling strategy in terms of number of replicates for a given, predetermined variability (Mouillot et al., 1999). Taylor's power law (Taylor, 1961) describes the spatial pattern of dispersion in a defined population and suggests that the mean $(\mathrm{X})$ and the variance $\left(\mathrm{s}^{2}\right)$ of a spatially distributed population are related by a power relation of the form: $\mathrm{s}^{2}=\mathrm{a} \times \mathrm{X}^{\mathrm{b}}$. The parameter "a" is the sampling factor that affects the variance/mean ratio. The parameter "b" is an index of the spatial distribution characteristics of the population, and has also been described as an index of aggregation that is independent of density, sample unit size and spatial pattern (Taylor, 1961 and 1984). These parameters are estimated by the intercept $\left(\log _{10}\right.$ a) and the regression coefficient (b) of the $\log _{10}$ of the sample variance on the $\log _{10}$ of the sample mean. This linear relationship allows us to estimate the optimum sample size $(\mathrm{N})$ for a given species, substrate and sampling site, following the relationship (Karandinos, 1976): $N=\left(1 / C^{2}\right) \times\left[\left(a \times X^{b}\right) /\right.$ $\left.\mathrm{X}^{2}\right]$, where $\mathrm{C}$ is the coefficient of variability defined by the ratio of the standard error of the mean (SE) to the arithmetic mean (X), i.e. the precision of the mean. $\mathrm{X}$ is the arithmetic mean of the species density. Parameters a and b are the two parameters of Taylor's power law for a given species and substrate.

Data were also treated with non parametric statistical tests: t test, Friedman, and Mann Whitney. Multiple comparisons for Friedman test were realised according to Siegel and Castellan (1988).

\section{Results}

\subsection{Accuracy of the quantification method}


The analysis of the sediment fraction remaining on a $80 \mu \mathrm{m}$ sieve showed that no resting cyst was retained. So this sieving did not represent an additional loss factor.

From the first exposure to ultrasound ( 3 minutes), we were able to obtain $87.0 \pm 2.5 \%$ (mean $\pm \mathrm{SE}$ ) of resting cysts on the total resting cysts which had been retained on a $20 \mu \mathrm{m}$ sieve during the 3 successive exposures. Second and third exposures allowed us to obtain respectively $10.5 \pm 2.2 \%$ and $2.5 \pm 1.2 \%$ of resting cysts. However, losses related to only one exposure were reduced.

Ultimately, the first extraction by Ludox CLX density gradient method gave a result of $48.0 \pm 5.0 \%$ (mean $\pm \mathrm{SE}$ ) of resting cysts on the total recovered after 6 extractions. However, the method yield strongly varied from $22.8 \%$ (minimal value) to $74.2 \%$ (maximal value). Few resting cysts were also recovered at the last extraction characterised by a yield $(1.7 \pm 0.7 \%)$ varying from 0.0 to $6.7 \%$. The number of recovered resting cysts and average variability were reduced progressively with extractions. The cumulative percentage of recovered resting cysts at the end of the 6 successive extractions reached nearly $90 \%$ at the $3^{\text {rd }}$ extraction (Fig. 4). The method yield (in cumulative percentage) significantly varied during extraction set (Friedman test, $\mathrm{p}<0.05$ ). Multiple comparisons (Siegel and Castellan, 1988) showed that the first and second extractions were not significantly different and that the method yield had not significantly increased after 4 extractions (Friedman test, $\mathrm{p}<0.05$ ).

Four successive extractions were necessary to extract resting cysts from one gram of sediment, but this protocol is tedious and time consuming, and so incompatible with mapping validation. Only one extraction is needed to recover nearly $50 \%$ of resting cysts from 1 gram of sediment without deviating significantly from the 11 replicate extraction rates which were 
obtained for this first extraction $(\mathrm{t}$ test, $\mathrm{p}<0.05)$. Although underestimating resting cysts density by a factor of 2 , we decided to use this procedure as a compromise between counting effort and measurement precision.

\subsection{Sampling strategy}

Whatever the analysed spatial scale, Taylor's power law established a significant linear relationship among the $\log _{10}$ of the variance and the $\log _{10}$ of the mean of resting cysts densities (Fig. 5). Sampling effort had to be extensively increased in order to improve the accuracy. However, when the curve $\mathrm{N}=\mathrm{f}(\mathrm{C})$ showed a plateau, the sampling effort that was needed was much higher than the gain in accuracy. For example within a spatial scale of 0.04 $\mathrm{m}^{2}$ with a resting cyst density of 10 cysts $\mathrm{g}^{-1}$ dry sediment, the decrease of $35 \%$ of the coefficient of variability was associated with an increase of sediment samples up to 20 . In contrast, when the curve $\mathrm{N}=\mathrm{f}(\mathrm{C})$ reached a plateau, the decrease of $5 \%$ of the coefficient of variability was related to an increase of sediment samples up to 180 .

Higher resting cyst density was associated with a less heterogeneous distribution, and consequently a better precision in their estimation (Table 2). For example within a spatial scale of $9 \mathrm{~m}^{2}$, the coefficient of variability reached nearly $50 \%$ when the resting cyst density

was 1 cyst $\mathrm{g}^{-1}$ dry sediment, whereas the coefficient of variability fell under $10 \%$ with a higher resting cyst density (1000 cyst $\mathrm{g}^{-1}$ dry sediment).

\subsection{Distribution mode of resting cysts}

For all the studied sampling stations $\left(\mathrm{A}_{00}, \mathrm{~A}_{3}, \mathrm{~A}_{6}\right.$, and $\left.\mathrm{C}_{5}\right)$, the distribution of $A$. catenella resting cysts was heterogeneous (Fig. 6) and the density variations were significant 
between 2 cores sampled at few meters or tens of centimeters apart (Table 3). Resting cysts densities and their associated variability measured on $9 \mathrm{~m}^{2}$ and $1 \mathrm{~m}^{2}$ spatial scales were not significantly different (Mann Whitney test, $\mathrm{p}<0.05$ ). Analysis of $\mathrm{b}$ parameters, which were obtained for each studied spatial scale (Fig. 5), clarified the previous results. Resting cysts aggregation in the sediment substrate varied with studied spatial scale. On a surface of approximately $0.04 \mathrm{~m}^{2}$ density variations of resting cysts were smaller $(b=1.18)$. Aggregation processes of resting cysts were higher on a $1 \mathrm{~m}^{2}$ surface $(b=1.45)$. However, the intensity of variations started to stabilize on a $9 \mathrm{~m}^{2}$ surface $(\mathrm{b}=1.66)$, and did not increase even if the spatial scale was increased beyond $9 \mathrm{~m}^{2}$ (on $2 \mathrm{~km}^{2}$ surface: $\mathrm{b}=1.60$ ).

A. catenella resting cysts were less abundant in $\mathrm{A}_{00}$ (Fig. 7a). Resting cysts density only reached $0.5 \pm 0.5$ cysts $\mathrm{g}^{-1}$ dry sediment in the upper $3 \mathrm{~cm}$ of sediment. A second density peak of $4.2 \pm 1.4$ cysts $\mathrm{g}^{-1}$ dry sediment was observed between 9 and $12 \mathrm{~cm}$ of sediment depth. In contrast, resting cysts were present from the surface to $18 \mathrm{~cm}$ deep in the sediment of station $\mathrm{A}_{3}$ (Fig. 7b). In the first 12 centimeters, resting cysts density varied from $14.0 \pm 7.0$ to $20.0 \pm 5.6$ cysts $\mathrm{g}^{-1}$ dry sediment. The highest resting cyst density was registered at the sediment surface. From 12 to $18 \mathrm{~cm}$ deep, resting cysts density was less than $1.2 \pm 0.6$ cysts $\mathrm{g}^{-}$

${ }^{1}$ dry sediment. In station $\mathrm{A}_{6}$, resting cysts were present from the surface to $18 \mathrm{~cm}$ deep (Fig. 7c). Down to $6 \mathrm{~cm}$, resting cysts density varied from 0 to $10.7 \pm 2.0$ cysts $\mathrm{g}^{-1}$ dry sediment. The highest resting cyst density was also registered in the upper sediment layer.

\section{Discussion}

The Ludox CLX density gradient method, with a single extraction, underestimates by a factor of 2 the density of $A$. catenella resting cysts present in one gram of sediment. Yamaguchi et al. (1995) reported a similar result with the ludox TM which showed that 
approximately half of resting cysts remained in the centrifugation pellet. In spite of these losses, and because of the very low concentration of resting cysts in sediments compared to organic and mineral matters (less than $1 \%$ of total sediment as reported by Persson and Rosenberg, 2003), this method appears to be rapid and selective for dinoflagellates resting cysts separation and quantification. The gradient density method gives the same results than that by direct counts, but with reduced analysis time (Erard-Le Denn and Boulay, 1995).

The extraction procedure of $80-20 \mu \mathrm{m}$ sediment fraction is not an additional loss factor for A. catenella resting cysts. Yamaguchi et al. (1995) showed that an increase of sonicating time was related to an increase of recovered resting cyst in the upper fraction before gradient density centrifugation.

Our methodological work supplements those carried out previously. Pospelova et al. (2004) used a sampling grid of $500 \mathrm{~m}$ mesh on average and sampled 3 sediment cores by station. Yamaguchi et al. (1996) increased sediment sampling and covered the whole studied area. The heterogeneous characteristic of resting cysts distribution in the sediment has been sometimes studied at sampling station spatial scale. Anderson et al. (1982) sampled several sediment cores for each studied stations (Table 1) and showed that the coefficient of variation between replicates could reach $45 \%$ and varied as a function of sampled station. More recently, investigators sampled 3 sediment cores for each studied station (Kremp, 2000; Kim et al., 2002; Irwin et al., 2003; Pospelova et al., 2004). Tsujino et al. (2002) sampled even up to 6 sediment cores. Other investigators (Marret and Scourse, 2002; McQuoid et al., 2002; Harland et al., 2004) used sampling methods which allowed to sample simultaneously several sediment cores (Table 1). However, the statistical relevance of such approaches was seldom specified. 
Variations of aggregation index (b) as a function of studied spatial scale give substance to developing a suitable sampling strategy. As the variability within a sediment core was lower than the variability between two sediment cores, it is better to increase sediment cores sampling than replicate counts in one sampled sediment core. Our results showed that strategy for sampling surfaces of $9 \mathrm{~m}^{2}$ and $1 \mathrm{~m}^{2}$ is nearly the same. According to preliminary numerical simulations, a resting cyst density of the order of $10^{2}$ cysts $\mathrm{g}^{-1}$ dry sediment seems to be sufficient for bloom initiation in our studied area (unpublished data). The optimum sampling strategy for sediment with $10^{2}$ cysts $\mathrm{g}^{-1}$ dry sediment is obtained from the best compromise between sampling effort and measuring precision. It consists of (i) sampling randomly three $(\mathrm{C}=28 \%)$ or ten stations $(\mathrm{C}=15 \%)$ according to study objectives (simple prospecting or more precise mapping); (ii) sampling randomly three sediment cores at each station $(\mathrm{C}=30 \%)$; (iii) counting only one replicate by sampled sediment core $(\mathrm{C}=18 \%)$.

For all studied spatial scales, $A$. catenella resting cysts distribution was heterogeneous in sediment. Garcés et al. (2004) mentioned a patchy distribution mode. However, heterogeneity was lower on small spatial scales of the order of ten square centimeters, and tends to stabilize itself starting beyond a surface of ten square meters. Similarly to Alexandrium minutum blooming in Brittany (France) (Erard-Le-Denn et al., 1993), the resting cysts density of A. catenella was higher in the upper 3 centimeters of sediment. A finer analysis showed that resting cysts of $A$. minutum were concentrated in the upper centimeter of sediment in the Catalan coast (Garcés et al., 2004). Our results showed that resting cysts density decreased rapidly with sediment depth. Such vertical profile pattern (Erard-Le-Denn et al., 1993; Garcés et al., 2004; Wang et al., 2004b) may reflect the influence of macro benthic organisms on resting cysts distribution (Tsujino et al., 2002) linked to biodiffusive bioturbation mode (François et al., 1999). Resting cysts occurrence down to $18 \mathrm{~cm}$ has been 
reported by Wang et al. (2004a). By determining vertical profiles, we can define an appropriate sedimentary layer for quantitative study of resting cysts distribution in a specific area. Even if the study of the upper $3 \mathrm{~cm}$ of sediment seems to be reasonable, it is preferable to proceed with a finer analysis linked with counts of resting cysts from the upper centimeter of the sediment.

\section{Conclusion}

Results related to the application of Taylor's power law are closely dependent on resting cyst density and aggregation in the given sediment. Each author has to carry out this pre-sampling effort for his own resting cysts-forming species, in his own area, in order to increase the accuracy of resting cyst mapping. Resting cysts density of the genus Alexandrium, which often reaches several hundreds to thousands of resting cysts by measuring unit (Table 1), suggests that sampling strategy will be less constraining. Through resting cysts mapping of Thau lagoon, we can identify preferential accumulation zones for resting cysts related to "hot spots" for bloom initiation. For this purpose, the water column will be regularly surveyed.

\section{Acknowledgements}

This study has been conducted under financial support from the Region LanguedocRoussillon and the Programme National d'Environnement Côtier (PNEC-France). Authors thank Ifremer LER/LR for its assistance and logistic support at sea, Jocelyne Oheix, Patrick Le Gall and Franck Lagarde for their participation in sediment sampling, Jeannette Krief for her technical support, and the Master student David Cherret for his participation to resting 
cysts quantification. We would like to thank Dr. Yves Collos and Dr. Claude Rougier for their helpful comments on the manuscript.

\section{References}

An K.H., Lassus P., Maggi P., Bardouil M., Truquet P., 1992. Dinoflagellate cyst changes and winter environmental conditions in Vilaine Bay, Southern Brittany (France). Bot. Mar. 35, 61-67.

Anderson D.M., 1997. Bloom dynamics of toxic Alexandrium species in the northern U.S. Limnol. Oceanogr. 42(5 part 2), 1009-1022.

Anderson D.M., Aubrey D.G., Tyler M.L., Coats W., 1982. Vertical and horizontal distributions of dinoflagellate cysts in sediments. Limnol. Oceanogr. 27(4), 757-765.

Anderson D.M., Stock C.A., Keafer B.A., Nelson A.B., Thompon B., McGuillicuddy Jr. D.J., Keller M., Matrai P.A., Martin J., 2005. Alexandrium fundyense cyst dynamics in the Gulf of Maine. Deep-Sea Res. II 52, 2522-2542.

Anderson D.M., Wall D., 1978. Potential importance of benthic cysts of Gonyaulax tamarensis and G. excavata in initiating toxic dinoflagellate blooms. J. Phycol. 14(2), 224-234.

Blanchard G.F., 1990. Overlapping microscale dispersion patterns of meiofauna and microphytobenthos. Mar. Ecol. Prog. Ser. 68, 101-111.

Blanco J., 1986. Separacion de quistes de dinoflagelados en gradiante de densidad. Oceanogr. 3, 181-184. (in Spanish).

Cho H-J., Matsuoka K., 2001. Distribution of dinoflagellate cysts in surface sediments from the Yellow Sea and East China Sea. Marine Micropaleontonlogy 42, 103-123. 
Dale B., 1983. Dinoflagellate resting cysts: "benthic plankton”. In: Fryxell, G.A. (Ed.), Survival strategies of the algae. Cambridge University. Press., Cambridge, pp. 69-136.

Erard-Le-Denn E., Boulay V., 1995. Resting cysts of Alexandrium minutum in marine sediments: quantification by three methods. In: Lassus, P., Arzul, G., Erard, E., Gentien, P., Marcaillou, C. (Eds), Harmful Marine Algal Blooms. Lavoisier Publishers, France, pp. 257-730.

Erard-Le-Denn, E., Desbruyeres, E., Olu, K., 1993. Alexandrium minutum: resting cyst distribution in the sediments collected along the Brittany coast, France. In: Smayda, T.J. and Shimizu, Y. (Eds.), Toxic Phytoplankton in the Sea. Elsevier Publishers, Amsterdam, pp. 109-114.

François F., Dalègre K., Gilbert F., Stora G., 1999. Variabilité spécifique à l'intérieur des groupes fonctionnels. Etude du remaniement sédimentaire de deux bivalves Venedridae, Ruditapes decussatus et Venerupis aurea. In: Elsevier (Ed), C. R. Acad. Sci. Paris Sciences de la Vie / Life Sciences 322, 339-345. (in French).

Garcés E., Bravo I., Vila M., Figueroa R.I., Maso M., Sampedro N., 2004. Relation between vegetative cells and cyst production during Alexandrium minutum bloom in Arenys de Mar harbour (NW Mediterranean). J. Plankton Res. 26(6), 637-645.

Garcés E., Maso M., Camp J., 1999. A recurrent and localized dinoflagellate bloom in a Mediterranean beach. J. Plankton Res. 21(12), 2373-2391.

Giangrande A., Montresor M., Cavallo A., Licciano M., 2002. Influence of Naineris Laevigata (Polychaeta: Orbiniidae) on vertical grain size distribution, and dinoflagellate resting stages in the sediment. J. Plankton Res. 47, 97-108.

Godhe A., Karunasagar I., Karlson B., 2000. Dinoflagellate cysts in recent marine sediments from SW India. Bot. Mar. 43, 39-48. 
Godhe A., Mcquoid M., 2003. Influence of benthic and pelagic environmental factors on the distribution of dinoflagellates cysts in surface sediment along the Swedish west coast. Aquat. Microb. Ecol. 32, 185-201.

Harland R., Nordberg K., Filipsson H.L., 2004. The seasonal occurrence of dinoflagellate cysts in surface sediments from Koljö Fjord, west coast of Sweden - a note. Rev. Palaeobot. Palynology 128, 107-117.

Ho C.C., 1993. Dispersion statistics and sample size estimates for Tetraynchus kanzawai (Acari: Tetranychidea) on mulberry. Environ. Entomol. 22, 21-25.

Irwin A., Hallegraeff G.M., McMinn A., Harrison J., Heijnis H., 2003. Cyst and radionuclide evidence demonstrate historic Gymnodinium catenatum dinoflagellate populations in Manukau and Hokianga Harbours, New Zealand. Harmful Algae 2, 61-74.

Joyce L.B., Pitcher G.C., 2004. Encystment of Zygabikodinium lenticulatum (Dinophyceae) during a summer bloom of dinoflagellates in the southern Benguela upwelling system. Estuar. Coast. Mar. Sci. 59, 1-11.

Joyce L.B., Pitcher G.C., du Randt A., Monteiro P.M.S., 2005. Dinoflagellate cysts from surface sediments of Saldanha Bay South Africa: an indication of the potential risk of harmful algal blooms. Harmful Algae 4, 309-318.

Karandinos M.G., 1976. Optimum sample size and comment on some published formulae. Bull. Entomol. Soc. Am. 22, 21-25.

Kim Y.O., Park M.H., Han M.S., 2002. Role of cyst germination in the bloom initiation of Alexandrium tamarense (Dinophyceae) in Masan Bay, Korea. Aquat. Microb. Ecol. 29, 279-286.

Kirn S.L., Townsend D.W., Pettigrew N.R., 2005. Suspended Alexandrium spp. hypnozygote cysts in the Gulf of Maine. Deep-Sea Res II 52: 2543-2559. 
Kremp A., 2000. Distribution, dynamics and in situ seeding potential of Scrippsiella hangoei (Dinophyceae) cyst populations from the Baltic Sea. J. Plankton Res. 22(11), 2155-2169.

Laabir M., Genovesi-Giunti B., Barré N., Vaquer A., Collos Y., Erard-Le-Denn E., Cecchi P., Pons V., Bibent B, 2004. The resting cyst of Alexandrium catenella, a dinoflagellate responsible for harmful algal blooms in Thau lagoon (Western French Mediterranean coast). In: Steidinger K.A., Landsberg J.H., Tomas C.R., Vargo G.A. (Eds.), Harmful Algae 2002. Florida Fish and Wildlife Conservation Commission, Florida Institute of Oceanography, and Intergovernmental Oceanographic Commission of Unesco, pp. 26-28.

Lilly E.L., Kullis D.M., Gentien P., Anderson D.M., 2002. Paralytic shellfish poisoning toxins in France linked to a human-introduced strain of Alexandrium catenella from the western Pacific: evidence from DNA and toxin analysis. J. Plankton Res. 24(5), 443-452.

Marret F., Scourse J., 2002. Control of modern dinoflagellate cyst distribution in the Irish and Celtic seas by seasonal stratification dynamics. Marine Micropaleontology 47, 101-116.

Matsuoka K., Joyce L.B, Kotani Y., Matsuyama Y., 2003. Modern dinoflagellate cysts in hypertrophic coastal waters of Tokyo Bay, Japan. J. Plankton Res. 25(12), 1461-1470.

McGillicuddy Jr. D.J., Signell R.P., Stock C.A., Keafer B.A., Keller M.D., Hetland R.D., Anderson D.M., 2003. A mechanism for offshore initiation of harmful algal blooms in the coastal Gulf of Maine. J. Plankton Res. 25(9), 1131-1138.

McQuoid M.R., Godhe A., Nordberg K., 2002. Viability of phytoplankton resting stages in the sediments of a coastal Swedish fjord. Eur. J. Phycol. 37, 191-201.

Mizushima K., Matsuoka K., 2004. Vertical distribution and germination ability of Alexandrium spp. Cysts (Dinophyceae) in the sediments collected from Kure Bay of the Seto Inland Sea, Japan. Phycol. Res. 52, 408-413.

Mouillot D., Culioli J-M., Lepretre A., Tomasini J-A., 1999. Dispersion statistics and sample size estimates for three fish species (Symphodus ocellatus, Serranus scriba and Diplodus 
annularis) in the Lavezzi Islands Marine Reserve (South Corsica, Mediterranean Sea). Mar. Ecol. 20(1), 19-34.

Persson A., Godhe A., Karlson B., 2000. Dinoflagellate cysts in recent sediments from the West Coast of Sweden. Bot. Mar. 43, 69-79.

Persson A., Rosenberg R., 2003. Impact of grazing and bioturbation of marine benthic deposit feeders on dinoflagellate cysts. Harmful Algae 2, 43-50.

Pospelova V., Chmura G.L., Walker H.A., 2004. Environmental factors influencing the spatial distribution of dinoflagellate cyst assemblages in shallow lagoons of southern New England (USA). Rev. Palaeobot. Palynol. 128, 7-34.

Schwinghamer P., Anderson D.M., Kulis D.M., 1991. Separation and concentration of living dinoflagellate resting cysts from marine sediments via density-gradient centrifugation. Limnol. Oceanogr. 36(3), 588-592.

Siegel S., Castellan N.J., 1988. Non parametric statistics for the behavioral sciences. McGraw-Hill Publishers, New York, 399 p.

Taylor L.R., 1961. Aggregation, variance and the mean. Nature 189, 732-735.

Taylor L.R., 1984. Assessing and interpreting the spatial distributions of insect populations. Annu. Rev. Entomol. 29, 321-357.

Thistlewood H.M.A., 1989. Spatial dispersion and sampling of Campylomma verbasci (Heteroptera: Miridae) on apple. Environ. Entomol. 18, 398-402.

Tsujino M., Kamiyama T., Uchida T., Yamaguchi M., Itakura S., 2002. Abundance and germination capability of resting cysts of Alexandrium spp. (Dinophyceae) from faecal pellets of macrobenthic organisms. J. Exp. Mar. Biol. Ecol. 271, 1-7.

Wang Z., Matsuoka K., Qi Y., Chen J., 2004a. Dinoflagellate cysts in recent sediments from Chinese Coastal Waters. Mar. Ecol. 25(4), 289-311. 
Wang Z., Matsuoka K., Qi Y., Chen J., Lu S., 2004b. Dinoflagellate cyst records in recent sediments from Daya Bay, South China Sea. Phycol. Res. 52, 396-407.

Wang Z., Qi Y., Lu S., Wang Y., Matsuoka K., 2004c. Seasonal distribution of dinoflagellate resting cysts in surface sediments from Changiiang River Estuary. Phycol. Res. 52, 387395.

Yamaguchi M., Itakura S., Imai I., Ishida Y., 1995. A rapid and precise technique for enumeration of resting cysts of Alexandrium spp. (Dinophyceae) in natural sediments. Phycologia 34(3), 207-214.

Yamaguchi M., Itakura S., Nagasaki K., Imai I., 1996. Distribution and abundance of resting cysts of the toxic dinoflagellates Alexandrium tamarense and A. catenella in sediments of the eastern Seto Inland Sea, Japan. In: Yasumoto T., Oshima Y., Fukuyo Y (Eds.). Intergovernemental Oceanographic Commission of UNESCO 1996, pp. 177-180. 


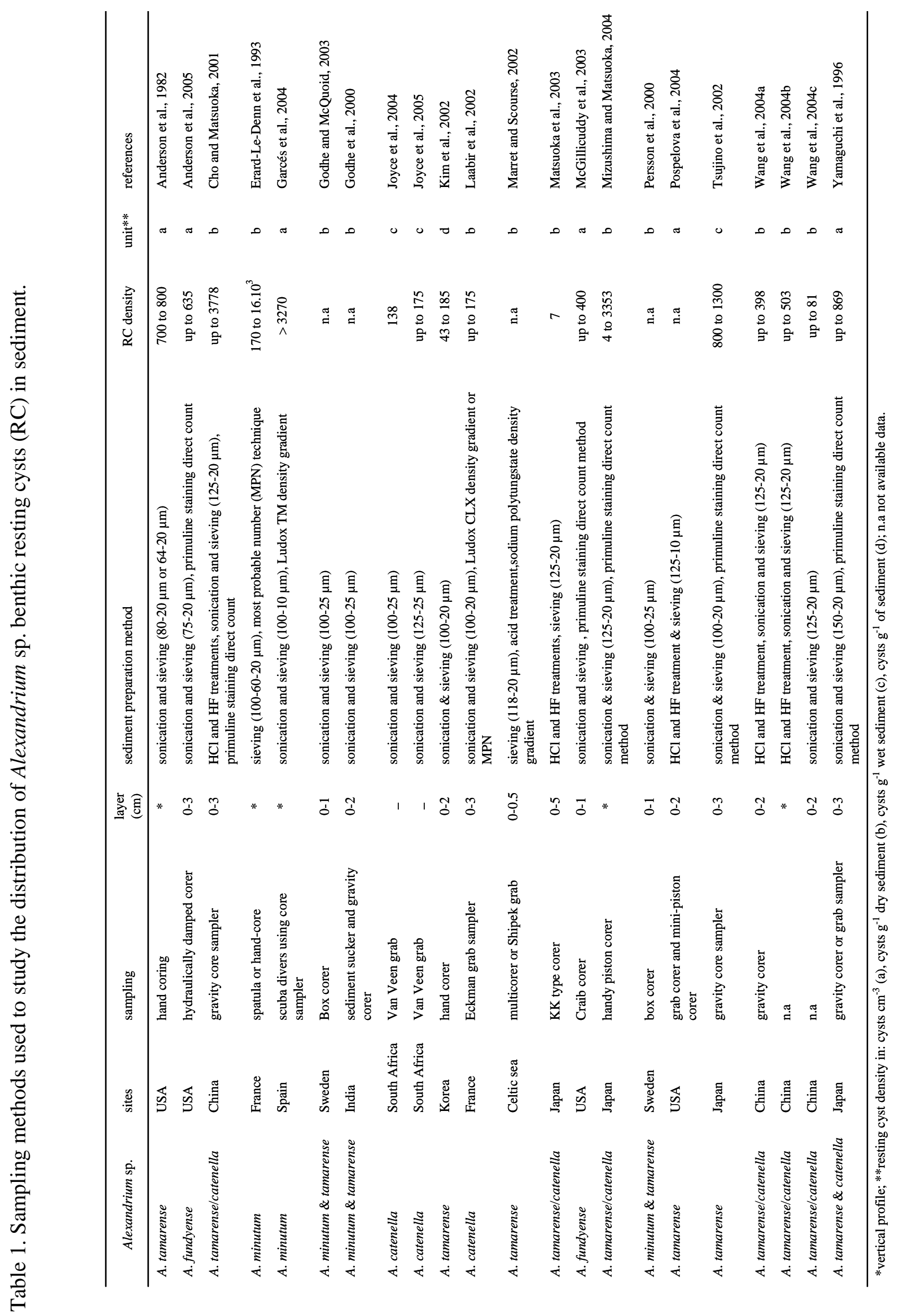


Table 2. Coefficient of variability (\%) related to a given resting cysts density (mean) and to 10 sampling of sediment for each studied spatial scales.

Resting cysts $\mathrm{g}^{-1}$ dry sediment

\begin{tabular}{lcccc} 
& 1 & 10 & 100 & 1000 \\
\hline $0.004 \mathrm{~m}^{2}$ & 36 & 14 & 5 & 2 \\
$1 \mathrm{~m}^{2}$ & 36 & 24 & 16 & 11 \\
$9 \mathrm{~m}^{2}$ & 49 & 26 & 14 & 7 \\
$2 \mathrm{~km}^{2}$ & 39 & 24 & 15 & 10
\end{tabular}


Table 3. Variations in the density of Alexandrium catenella resting cysts in the sediment of stations $\mathrm{A}_{00}, \mathrm{~A}_{3}, \mathrm{~A}_{6}$, and $\mathrm{C}_{5}$ on $9 \mathrm{~m}^{2}$ and $1 \mathrm{~m}^{2}$ surfaces.

\begin{tabular}{ccccc}
\hline \multirow{2}{*}{$\begin{array}{c}\text { sampling } \\
\text { station }\end{array}$} & surface & mean $\pm \mathrm{SE}$ & minimal value & maximal value \\
\cline { 3 - 5 } & & \multicolumn{3}{c}{ cysts $\mathrm{g}^{-1}$ dry sediment } \\
$\mathrm{A}_{00}$ & $9 \mathrm{~m}^{2}$ & $2.4 \pm 0.8$ & 0.0 & 10.6 \\
& $1 \mathrm{~m}^{2}$ & $1.6 \pm 0.7$ & 0.0 & 10.3 \\
\hline \multirow{2}{*}{$\mathrm{A}_{3}$} & $9 \mathrm{~m}^{2}$ & $53.7 \pm 7.3$ & 25.6 & 130.7 \\
& $1 \mathrm{~m}^{2}$ & $51.8 \pm 6.1$ & 21.3 & 89.0 \\
\hline & $9 \mathrm{~m}^{2}$ & $12.2 \pm 2.6$ & 0.0 & 33.9 \\
& $1 \mathrm{~m}^{2}$ & $6.8 \pm 1.9$ & 0.0 & 26.0 \\
\hline & $9 \mathrm{~m}^{2}$ & $9.3 \pm 2.7$ & 0.0 & 43.8 \\
$\mathrm{C}_{5}$ & $1 \mathrm{~m}^{2}$ & $9.8 \pm 2.9$ & 0.0 & 43.8 \\
\hline
\end{tabular}


Figure caption

Fig. 1. Maps of Thau lagoon located $30 \mathrm{~km}$ South-West of the city of Montpellier (Hérault, South France). Shellfish farming sectors (dash lines) represent 1/5 of total surface of the lagoon. The sampling grid of creek of l'Angle is composed by 27 GPS stations with a mesh of $100 \mathrm{~m}$.

Fig. 2. Method developed for sampling sediments of stations $A_{00}, A_{3}, A_{6}$ and $C_{5}$ located on the creek of l'Angle sampling grid. Sampling system allowed to sample 28 sediment cores at each station and was composed by a quadrat $(3 \mathrm{~m} \times 3 \mathrm{~m})$ divided by a mesh of $1 \mathrm{~m} \times 1 \mathrm{~m}$ and by a central sub-quadrat $(1 \mathrm{~m} \times 1 \mathrm{~m})$ divided by a mesh of $0.33 \mathrm{~m} \times 0.33 \mathrm{~m}$.

Fig. 3. Protocol of resting cysts separation from sediment including the preparation of the sediment fine fraction and the centrifugation by Ludox CLX density gradient. The accuracy of the method was tested at three crucial steps: $80 \mu \mathrm{m}$ sieving, density gradient formation and duration of sonication.

Fig. 4. Evolution of cumulative percentage of recovered resting cysts at the end of the 6 successive extractions with centrifugation by Ludox CLX density gradient ( $\mathrm{n}=11$ replicates).

Fig. 5. Regressions obtained by the application of Taylor's power law showed a linear relationship among the $\log _{10}$ of the sample variance on the $\log _{10}$ of the sample mean for Alexandrium catenella resting cysts density obtained within different spatial scales. For each spatial scale, the relationship is significant $(\mathrm{p}<0.001)$. The parameters of Taylor's power law are: (a) $\mathrm{a}=1.35$ and $\mathrm{b}=1.18$ within a spatial scale of $0.04 \mathrm{~m}^{2}$; (b) $\mathrm{a}=1.58$ and $\mathrm{b}=1.45$ 
within a spatial scale of $1 \mathrm{~m}^{2}$; (c) $\mathrm{a}=1.29$ and $\mathrm{b}=1.66$ within a spatial scale of $9 \mathrm{~m}^{2}$; (d) $\mathrm{a}=$ 1.35 and $\mathrm{b}=1.60$ within a spatial scale of $2 \mathrm{~km}^{2}$.

Fig. 6. Density and distribution of Alexandrium catenella resting cysts respectively on $9 \mathrm{~m}^{2}$ surface with $1 \mathrm{~m}$ mesh $\left(^{*}\right)$ and $1 \mathrm{~m}^{2}$ surface with $0.33 \mathrm{~m}$ mesh (**) in sediment of stations $\mathrm{A}_{00}$ (a), $A_{3}(b), A_{6}(c)$ and $C_{5}(d)$ of the creek of l'Angle sampling grid. Black cones refer to black circle in figure 2.

Fig. 7. Density (mean $\pm \mathrm{SE}$ ) of Alexandrium catenella resting cysts observed along vertical profiles in sediments of stations $\mathrm{A}_{00}(\mathrm{a}), \mathrm{A}_{3}(\mathrm{~b})$ and $\mathrm{A}_{6}(\mathrm{c})$ of the creek of l'Angle sampling grid. 

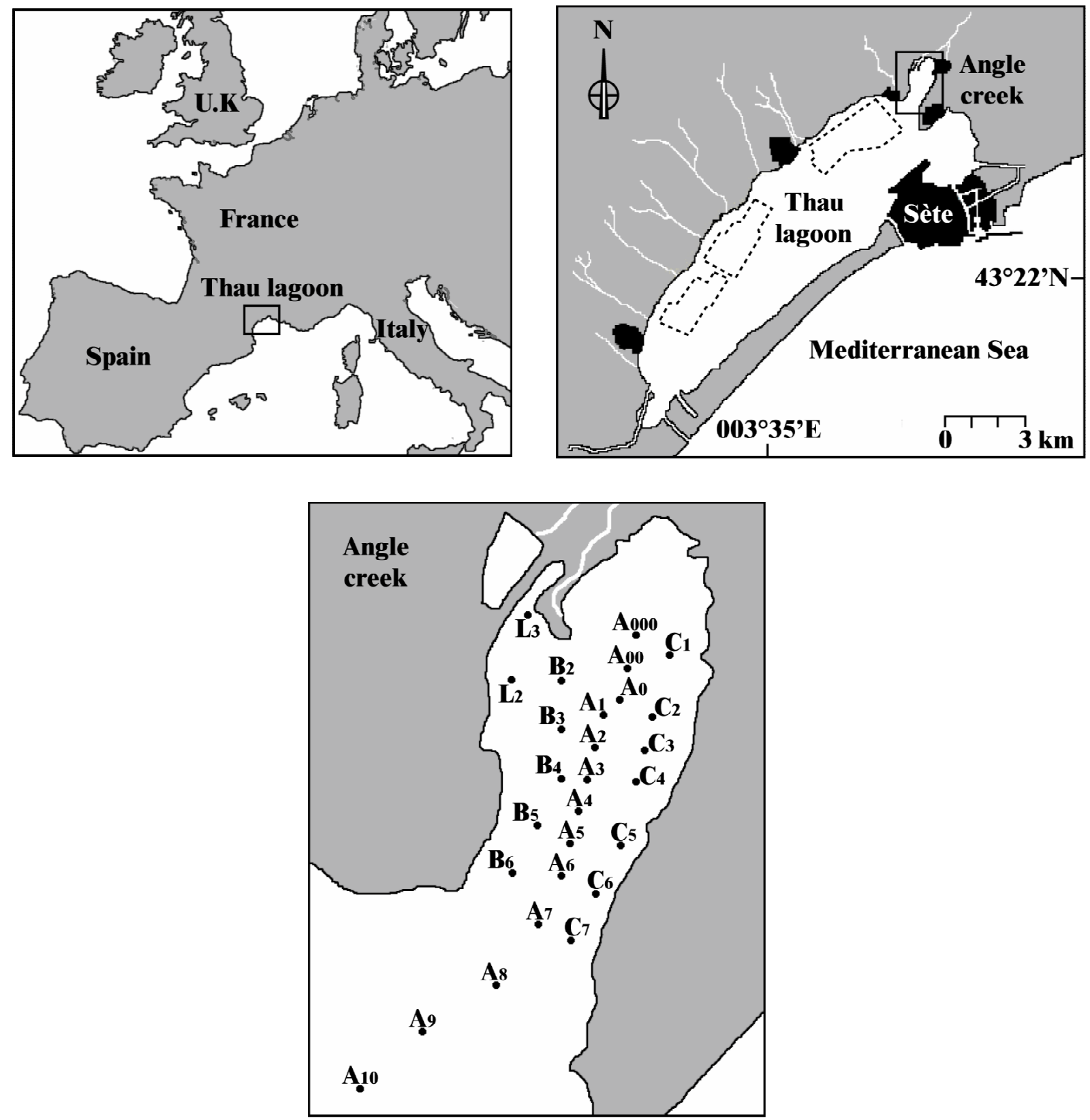

Figure 1 


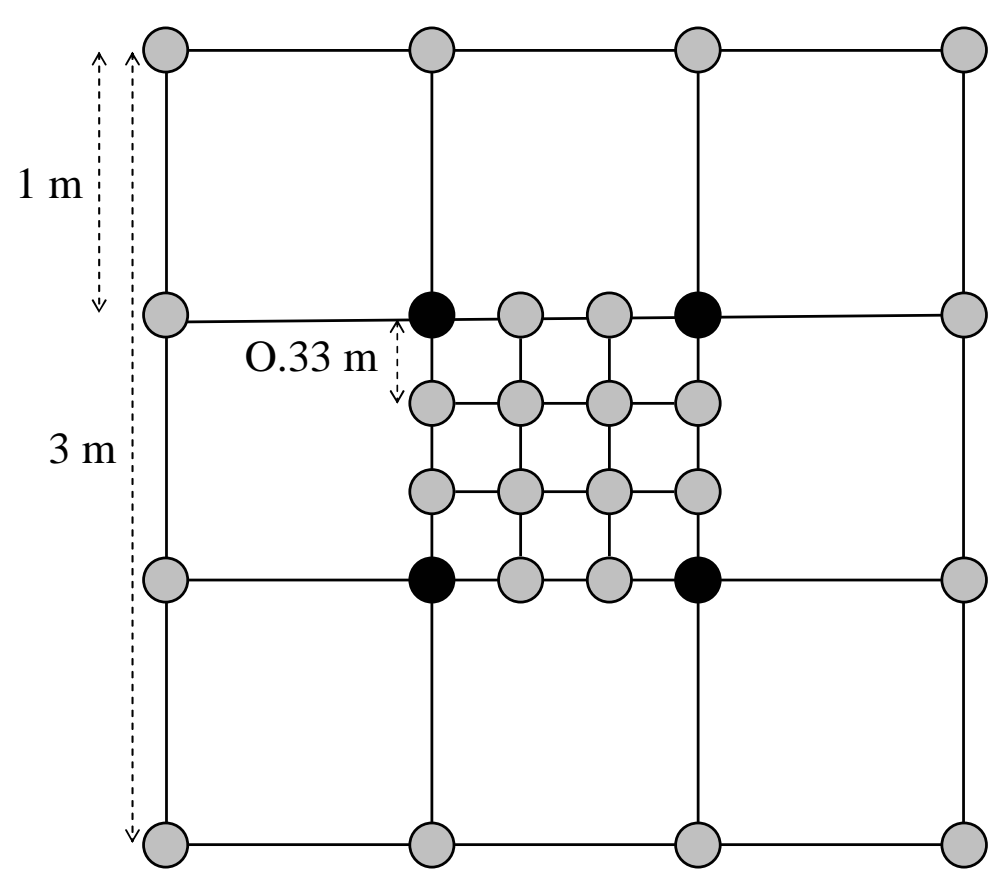

Figure 2 


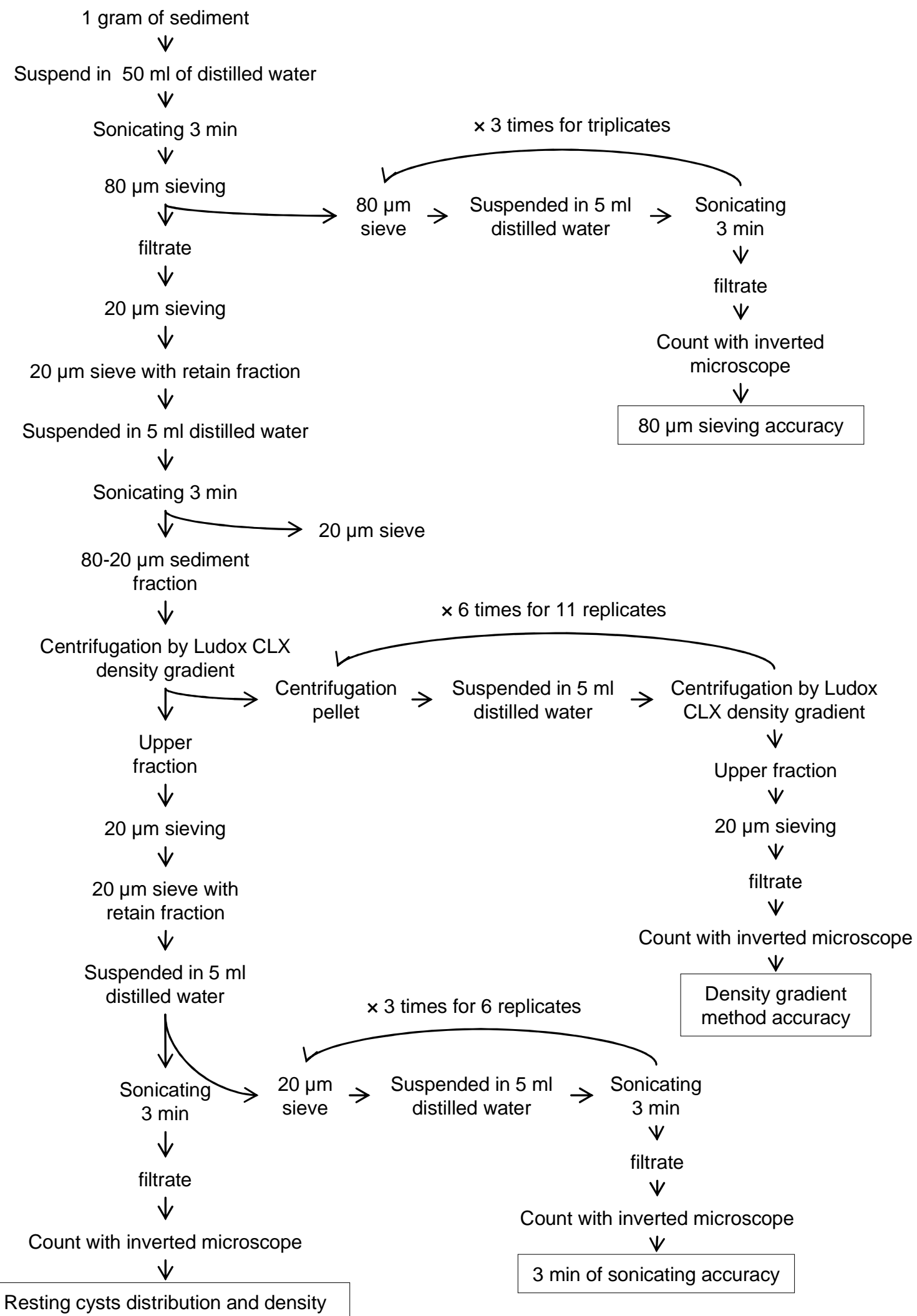

Figure 3 


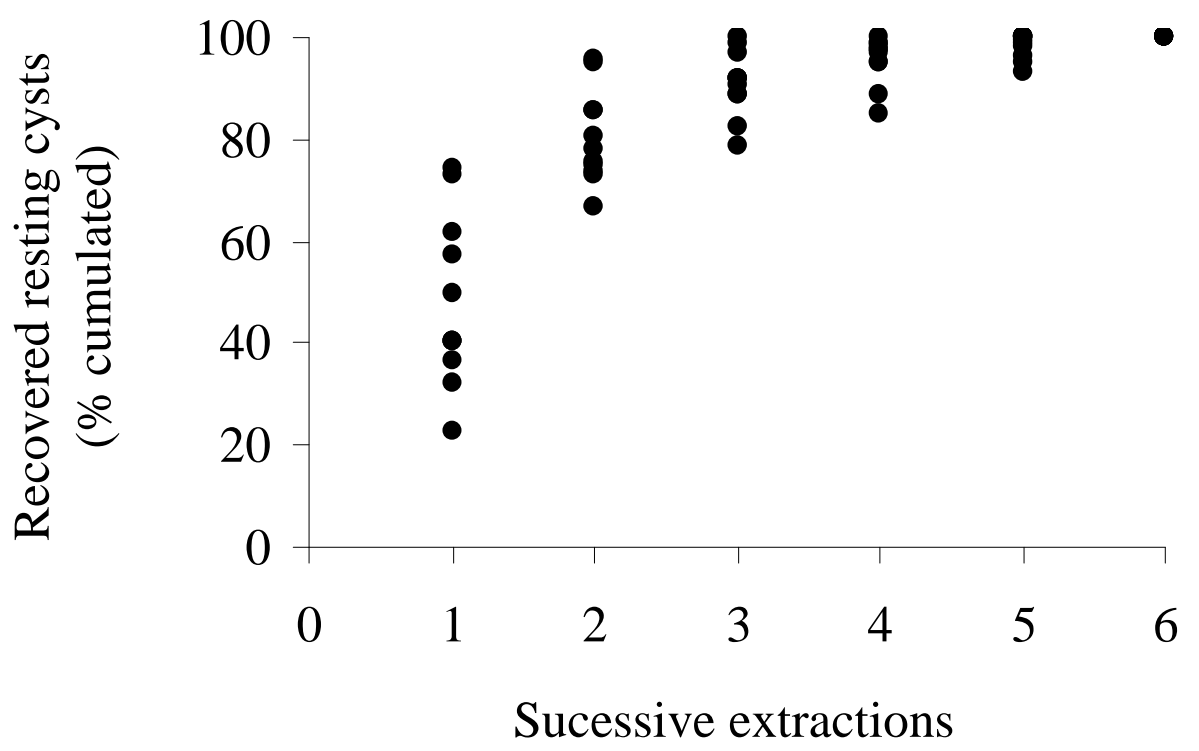

Figure 4 

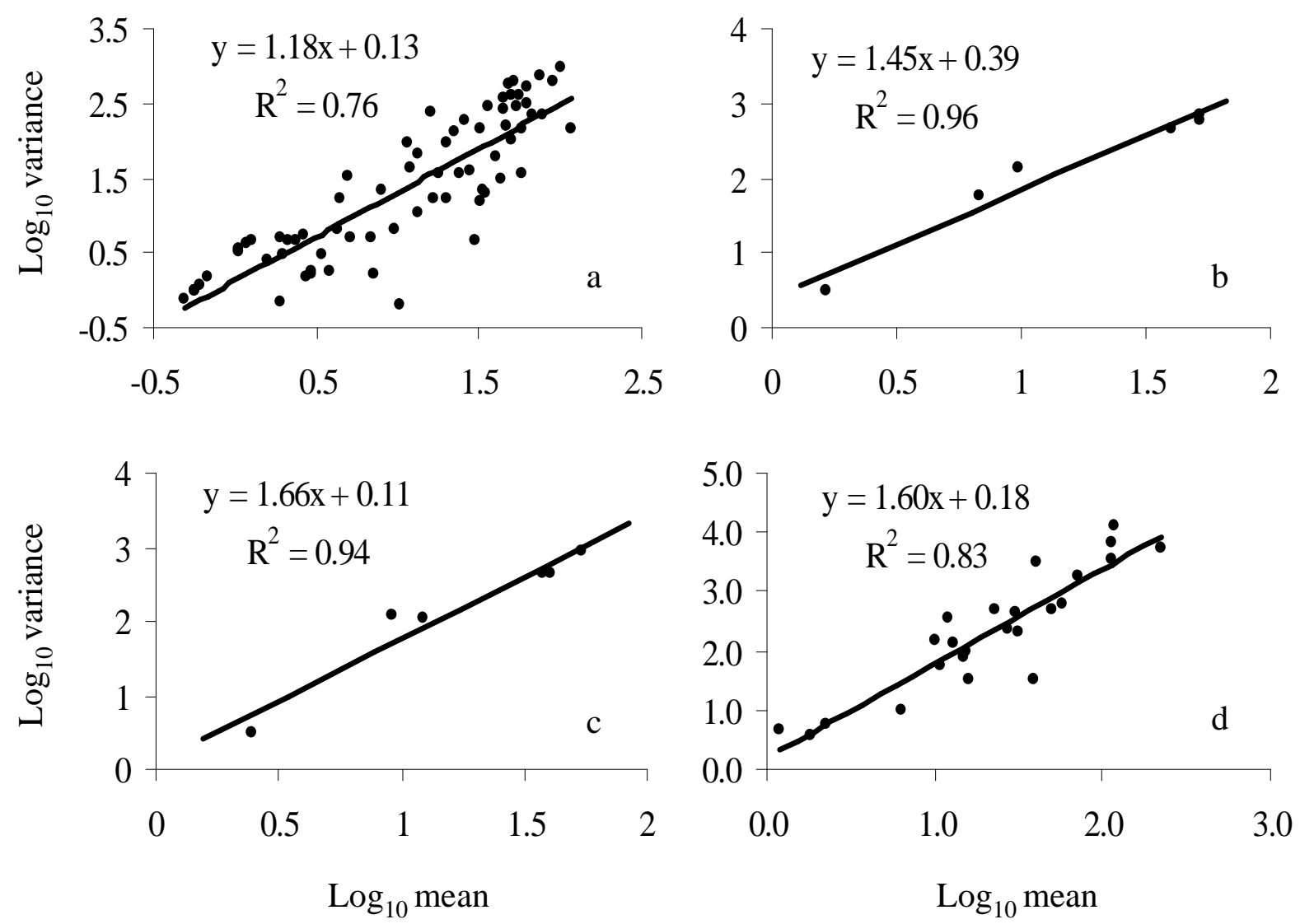

Figure 5 

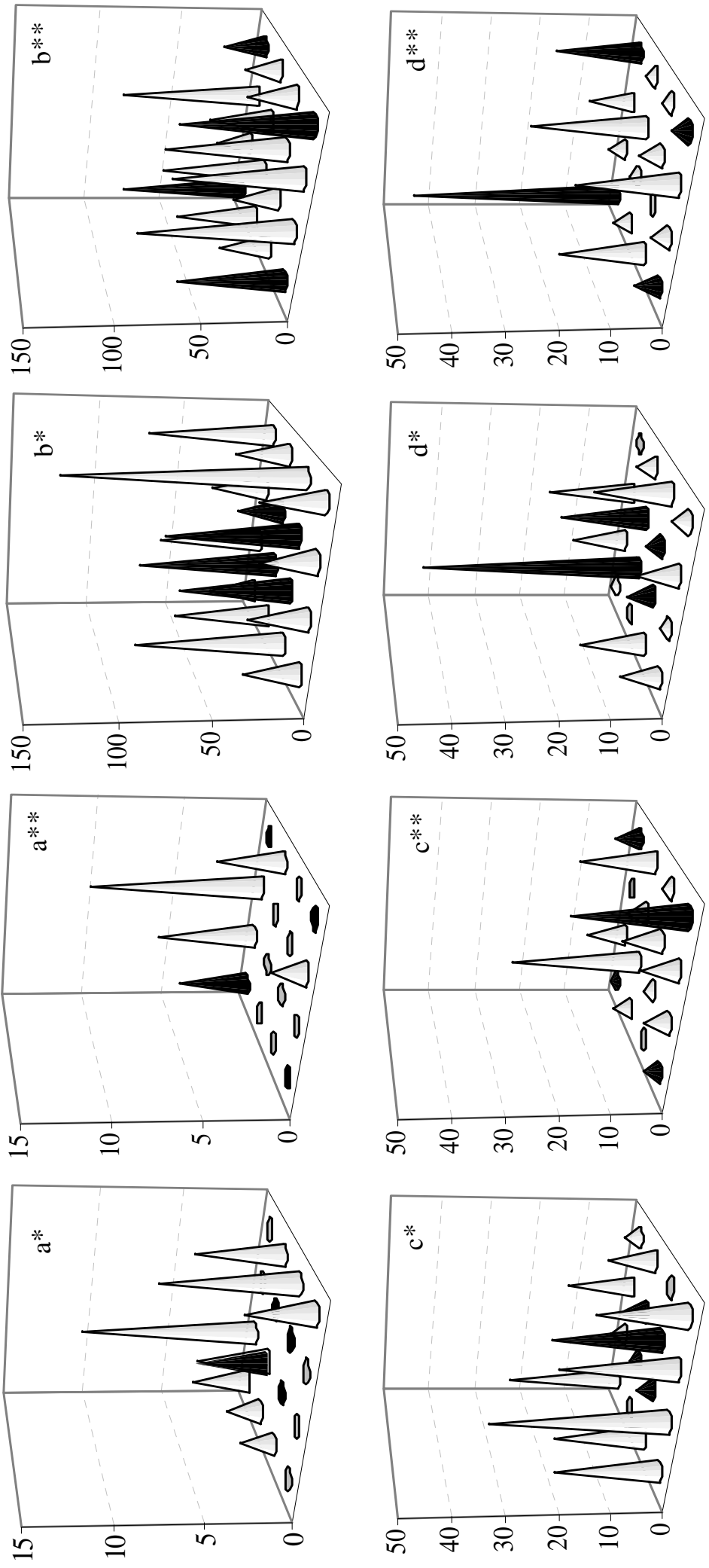

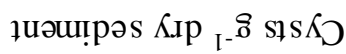

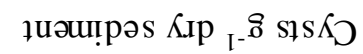

Figure 6 
34

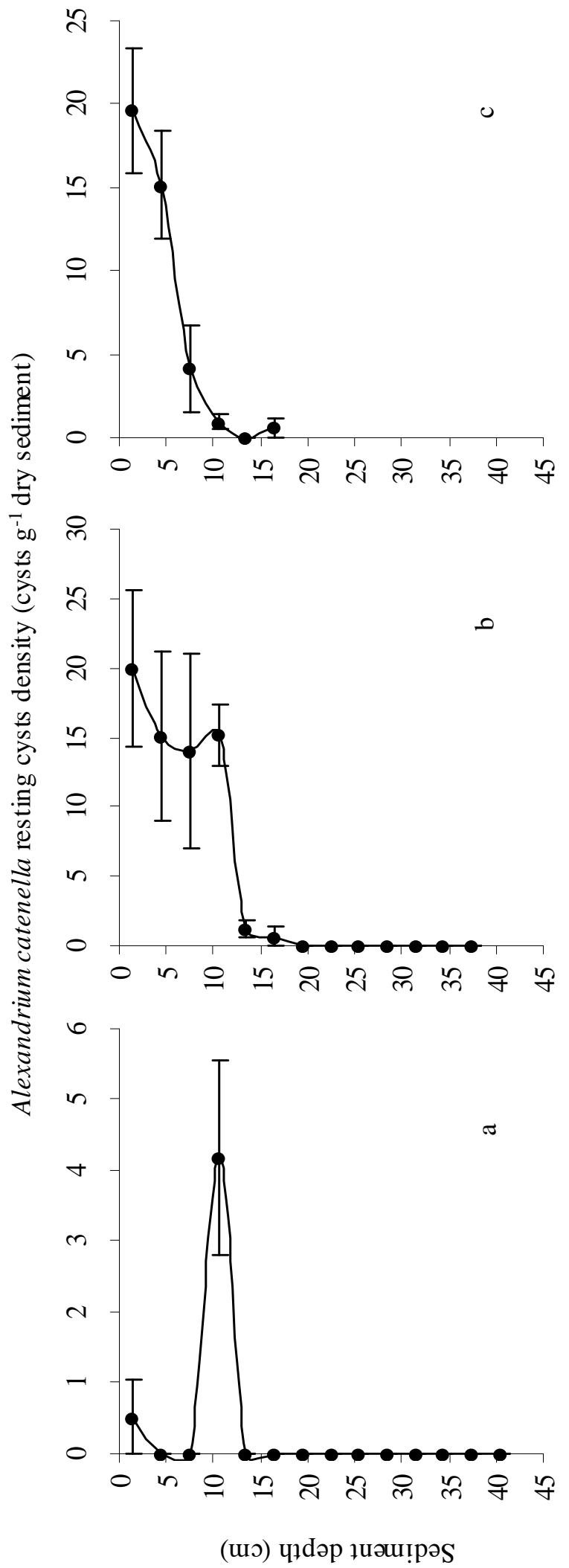

Figure 7 